\title{
Influence of consumption of probiotics on presence of enterobacteria in the oral cavity
}

\section{Mariella Vieira Pereira Leão(a) Ricardo Coelho Cassia(a) Silvana Soléo Ferreira dos Santos ${ }^{(a)}$ \\ Célia Regina Gonçalves e Silva(a) Antônio Olavo Cardoso Jorge ${ }^{(b)}$}

(a) Bioscience Basic Institute, University of Taubaté, Taubaté, SP, Brazil.

(b) Department of Bioscience and Oral Diagnosis, School of Dentistry of São José dos Campos, Unesp - São Paulo State University, São José dos Campos, SP, Brazil.

Declaration of Interests: The authors certify that they have no commercial or associative interest that represents a conflict of interest in connection with the manuscript.

Corresponding author:

Mariella Vieira Pereira Leão

E-mail:mariellaleao@yahoo.com.br

Received for publication on Jun 02,2011 Accepted for publication on Aug 12, 2011

\begin{abstract}
Clinical benefits of probiotics have been clearly reported in different gastrointestinal disorders, many of them caused by enterobacteria. The oral cavity is a port of entry and can be an important reservoir of these microorganisms. This work evaluated whether consumption of probiotics was able to influence the presence of enterobacteria in the oral cavity and the specific secretory response against these microorganisms. Saliva samples of healthy individuals were collected and plated in MacConkey agar. Carriers of Gram-negative, rod-shaped microorganisms in the oral cavity were selected and instructed to use the probiotic Yakult LB for 20 days. Saliva was then collected and enterobacteria species were identified using the API 20 E system and by ELISA using anti-enterobacteria IgA. The results showed reduction in the prevalence of enterobacteria, but no significant changes in enterobacterial counts (log CFU/ $\mathrm{mL} ; p=0.3457)$. The species most frequently isolated were Enterobacter cloacae and Klebsiella oxytoca, both before and after probiotic consumption. No significant changes were observed in anti-enterobacteria IgA levels. In conclusion, probiotic consumption had some influence on enterobacterial presence in the oral cavity, but did not affect enterobacterial counts or the specific immune secretory response against them.
\end{abstract}

Descriptors: Lactobacillus casei; Bifidobacterium; Enterobacteriaceae; Probiotics.

\section{Introduction}

Probiotics are food supplements containing live microorganisms or microbial cell components that promote host health. ${ }^{1}$ Clinical benefits of probiotics have been clearly documented for different gastrointestinal disorders (e.g., lactose intolerance, viral and bacterial gastroenteritis, and inflammatory bowel disease ${ }^{2}$ ) and in immunotherapy against cancer and allergies. ${ }^{3}$ The presence of probiotic microorganisms in intestinal mucosa can prevent the colonization of pathogens, probably via competitive effects, production of antimicrobial substances, and/or modulation of mucosal immunity. ${ }^{4-6}$

Shu et al. ${ }^{7}$ observed that the consumption of probiotic bacteria induced a reduction in diarrhea caused by Escherichia coli toxin in pigs. The authors also observed an increase in phagocyte activity and in levels of IgA antibodies, reducing the mortality caused by E. coli 0157:H7 in mice. ${ }^{8}$ Jespersen $^{9}$ observed an inhibitory effect of probiotics in pathoge- 
nicity of Salmonella typhimurium, Shigella flexneri, and Clostridium difficile in infant acute gastroenteritis.

The oral cavity is a port of entry for many microorganisms and can be an important reservoir of enterobacteria. These microorganisms are potential agents in gastrointestinal disorders, hospital infections, and aggravation of oral disease. ${ }^{10} \mathrm{An}$ increased knowledge about products that may inhibit the adherence or growth of these bacteria is important and essential. Thus, the objective of the present study was to analyze whether consumption of the probiotic Yakult LB influences the presence of enterobacteria in oral cavity and the specific immune secretory response against these microorganisms.

\section{Methodology}

The study was based on Santos et al. ${ }^{11}$ and was approved by the Local Research Ethics Committee according to the Declaration of Helsinki. Healthy young individuals were selected, excluding those who had used antibiotics for a period of 3 months, who were smokers, or who wore oral prosthesis or orthodontic devices. All participants were fully informed concerning the objectives and methodology of the study and provided written free and informed consent.

Initially, 112 individuals were analyzed and saliva samples were collected without stimulation. Carriers of Gram-negative, rod-shaped microorganisms in the oral cavity were selected for a second collection 1 month later. Individuals who tested positive both times were instructed to use the probiotic Yakult LB ${ }^{\circledR}$ (Yakult S/A Indústria e Comércio, Lorena, Brazil) (Lactobacillus casei at $2 \times 10^{7}$ to $10^{9}$ and Bifidobacterium breve at $5 \times 10^{7}$ to $10^{9} \mathrm{CFU} /$ $\mathrm{mL}$ ) daily for 20 days. After this period, another saliva sample was collected from each subject.

All samples were plated in duplicate in MacConkey agar (Oxoid, Lawrence, USA) and incubated at $37{ }^{\circ} \mathrm{C}$ for $24-48 \mathrm{~h}$. The number of colony forming units per milliliter of saliva $(\mathrm{CFU} / \mathrm{mL})$ was determined. Suggestive colonies from each plate were confirmed by smear tests stained by the Gram technique. Enterobacteria species were identified using the API 20 E system (BioMérieux, Craponne, France).
Levels of anti-enterobacterial $\operatorname{Ig} \mathrm{A}$ were also analyzed by ELISA. Sensitization of ELISA plates was performed using a pool of enterobacteria cells isolated from the oral cavity of participants, which was killed with formaldehyde and then diluted in $0.1 \mathrm{M}$ carbonate-bicarbonate buffer, $\mathrm{pH}$ 9.6, at a final concentration of $10^{9}$ cells $/ \mathrm{mL}$. The ELISA plates were then incubated with diluted saliva (1:10), followed by anti-human IgA labeled with horseradish peroxidase. The reaction was developed with orthophenylenediamine and $\mathrm{H}_{2} \mathrm{O}_{2}$ as substrate. Absorbance was measured at $496 \mathrm{~nm}$.

$\mathrm{CFU} / \mathrm{mL}$ counts and anti-enterobacteria IgA levels before and after use of probiotics were compared by analysis of variance (ANOVA) for paired samples with a $5 \%$ level of significance $(p<0.05)$.

\section{Results}

From 112 initial saliva samples, 42 (37.5\%) were carriers of Gram-negative rod-shaped microorganisms. Of these, $38(90.5 \%)$ tested positive again 1 month after the first collection. Of these, 20 individuals were included in this study after losses due to voluntary withdrawal, lack of compliance, and use of antibiotics.

After taking probiotic for 20 days, 5/20 individuals no longer tested positive for enterobacteria, indicating a $25 \%$ reduction in the prevalence of enterobacteria in the oral cavity. A reduction in enterobacterial counts was also observed in most of the subjects (Figure 1). However, there was no significant difference between the mean $\log \mathrm{CFU} / \mathrm{mL}$ before and after probiotic consumption ( $p=0.3457)$ (Figure 2).

Eight species of enterobacteria were identified before probiotic consumption, whereas six were identified after. The most frequently isolated species, both before and after consumption, was Enterobacter cloacae, followed by Klebsiella oxytoca (Table 1). The use of probiotic did not significantly change the amounts of either species. The species isolated from each individual before and after probiotic consumption are shown in Table 2. E. sakazaki, Pantoa spp., E. amnigenus, and Serratia odorifera 1 were found only before consumption; S. marcescens and Citrobacter freundii were found only after consumption. 


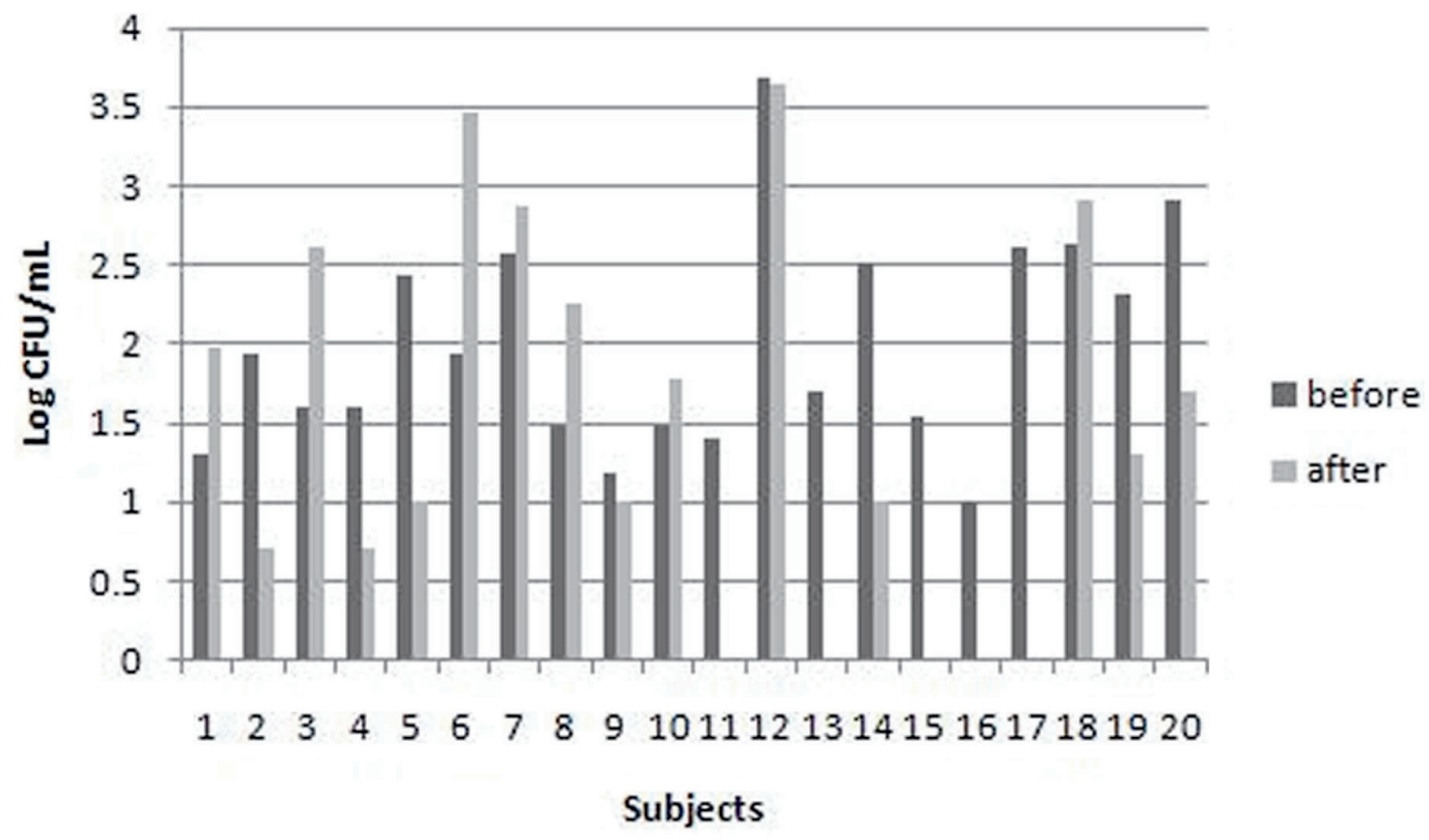

Figure 1 - Comparison between mean $\log$ CFU/mL in saliva before and after probiotic consumption for each individual subject.

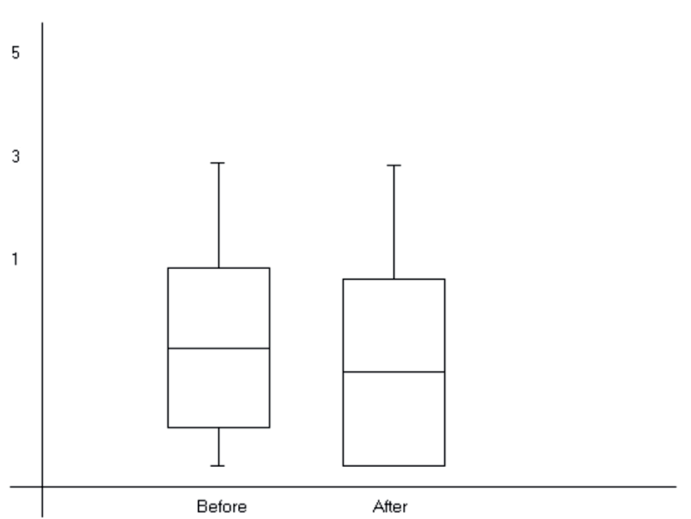

Figure 2 - Mean $\log \mathrm{CFU} / \mathrm{mL}$ of enterobacteria isolated from the oral cavity before and after probiotics $(p=0.3457)$.

Immunological analysis showed no significant changes in the level of anti-enterobacteria $\operatorname{IgA}$ $(p=0.1215)$ (Figure 3) and there was no correlation between IgA levels and CFU/mL counts (data not shown).

\section{Discussion}

Enterobacteria are considered part of the transient microbiota of the oral cavity, but colonization can persist for years and may favor transmission of

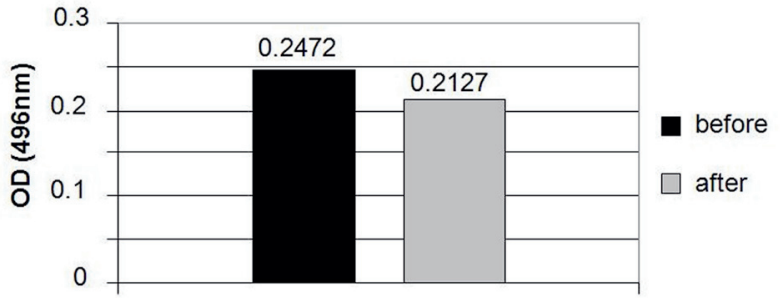

Figure 3 - Mean optical density $\left(O D_{496}\right)$ corresponding to levels of anti-enterobacteria $\lg \mathrm{A}$ in saliva before and after probiotics ( $p=0.1215)$.

these microorganisms. ${ }^{10}$ Buehlmann et al. ${ }^{10}$ studied a decolonization regimen of antibiotics or mouth rinse with $0.2 \%$ chlorhexidine for eradication of extended-spectrum $\beta$-lactamase-producing Enterobacteriaceae $(\mathrm{ESBL})$ in infected or colonized patients. They observed that $76 \%$ of patients became negative for ESBL at follow-up, suggesting that the program could be beneficial in a select group of patients, potentially shortening duration of ESBL colonization and subsequently reducing the risk for transmission. Some in vitro studies have demonstrated that probiotics present antimicrobial activity against some bacteria of the Enterobacteriaceae family and can prevent their adhesion to epithelial cells. ${ }^{12,13}$ 
Table 1 - Log CFU/mL of E. cloacae and K. oxytoca before and after probiotic consumption

\begin{tabular}{|c|c|c|c|c|}
\hline & \multicolumn{2}{|c|}{ E. cloacae } & \multicolumn{2}{|c|}{ K. oxytoca } \\
\hline & Before & After & Before & After \\
\hline & 0.0000 & 1.7782 & 1.3010 & 1.5441 \\
\hline & 1.6021 & 0.6990 & 1.6021 & 2.5250 \\
\hline & 2.4393 & 1.0000 & 1.9294 & 2.8451 \\
\hline & 2.5740 & 2.8603 & 1.3010 & 0.0000 \\
\hline & 0.0000 & 3.3324 & 1.3979 & 0.0000 \\
\hline & 0.0000 & 2.0414 & 1.6990 & 0.0000 \\
\hline & 1.1761 & 0.6990 & 1.9031 & 1.0000 \\
\hline & 1.1761 & 1.7782 & 1.0000 & 0.0000 \\
\hline & 3.6812 & 3.6435 & 1.3979 & 1.0000 \\
\hline & 2.6233 & 2.9031 & & \\
\hline & 2.9031 & 1.6990 & & \\
\hline Mean & 1.6523 & 2.0395 & 1.5035 & 0.9905 \\
\hline St dev & 1.2938 & 1.0291 & 0.3055 & 1.1195 \\
\hline$p$ value & \multicolumn{2}{|c|}{0.2664} & \multicolumn{2}{|c|}{0.2268} \\
\hline
\end{tabular}

The present work showed that probiotic consumption was able to reduce the number of people carrying enterobacteria in the oral cavity by $25 \%$, suggesting a possible role for the product in decolonization. This phenomenon could be useful in hospital environments to reduce the prevalence of these microorganisms among medical professionals and consequently reduce transmission, since the infections caused by enterobacteria are usually difficult to treat. ${ }^{10}$

Although $25 \%$ of tested subjects no longer carried enterobacteria, others showed an increase in counts, so that no significant change was seen in the mean enterobacteria counts before and after probiotics. Brown et al. ${ }^{14}$ also observed no significant changes in E. coli, Klebsiella, and Enterobacter counts in feces of healthy adults who consumed food containing probiotic bacteria on a daily basis. Thus, a mutually beneficial relationship between the probiotic species and some enterobacteria species cannot be ruled out. Moreover, there is a possibility that probiotic consumption favors the adherence of enterobacteria in the oral cavity of non-carrier individuals, who were not studied, possibly resulting in no net change in prevalence.
Table 2 - Species and abundance of enterobacteria isolated from the oral cavity of each healthy individual before and after probiotic consumption.

\begin{tabular}{|c|c|c|c|c|}
\hline \multirow{2}{*}{ Individual } & \multicolumn{2}{|c|}{ Species } & \multicolumn{2}{|c|}{ Log CFU/mL } \\
\hline & Before & After & Before & After \\
\hline \multirow{2}{*}{7} & - & E. cloacae & 0.000 & 1.778 \\
\hline & K. oxyłoca & K. oxyłoca & 1.301 & 1.544 \\
\hline 36 & E. aerogenes & E. aerogenes & 1.929 & 0.699 \\
\hline \multirow{2}{*}{44} & K. oxyłoca & K. oxyłoca & 1.602 & 2.525 \\
\hline & - & C. freundii & 0.000 & 1.813 \\
\hline 50 & E. cloacae & E. cloacae & 1.602 & 0.699 \\
\hline 72 & E. cloacae & E. cloacae & 2.439 & 1.000 \\
\hline \multirow{2}{*}{73} & K. oxyłoca & K. oxytoca & 1.929 & 2.845 \\
\hline & - & E. cloacae & 0.000 & 3.332 \\
\hline 74 & E. cloacae & E. cloacae & 2.574 & 2.860 \\
\hline \multirow{4}{*}{75} & E. sakazakii & - & 1.000 & 0.000 \\
\hline & - & E. cloacae & 0.000 & 2.041 \\
\hline & - & S. marcescens & 0.000 & 1.845 \\
\hline & K. oxyłoca & - & 1.301 & 0.000 \\
\hline \multirow{2}{*}{81} & E. cloacae & E. cloacae & 1.176 & 0.699 \\
\hline & - & S. liquefaciens & 0.000 & 0.699 \\
\hline \multirow{2}{*}{90} & E. cloacae & E. cloacae & 1.176 & 1.778 \\
\hline & Pantoa spp. 2 & - & 1.176 & 0.000 \\
\hline 96 & K. oxyłoca & - & 1.398 & 0.000 \\
\hline 97 & E. cloacae & E. cloacae & 3.681 & 3.643 \\
\hline 98 & K. oxyłoca & - & 1.699 & 0.000 \\
\hline \multirow{2}{*}{100} & K. oxyłoca & K. oxytoca & 1.903 & 1.000 \\
\hline & S. liquefaciens & - & 2.398 & 0.000 \\
\hline \multirow{2}{*}{101} & Pantoa spp. 2 & - & 1.301 & 0.000 \\
\hline & S. odorifera 1 & - & 1.176 & 0.000 \\
\hline 102 & K. oxyłoca & - & 1.000 & 0.000 \\
\hline 108 & S. liquefaciens & - & 2.602 & 0.000 \\
\hline 109 & E. cloacae & E. cloacae & 2.623 & 2.903 \\
\hline \multirow{4}{*}{110} & E. sakazakii & - & 1.813 & 0.000 \\
\hline & - & E. aerogenes & 0.000 & 1.000 \\
\hline & K. oxyłoca & K. oxytoca & 1.398 & 1.000 \\
\hline & E. amnigenus & - & 2.079 & 0.000 \\
\hline 112 & E. cloacae & E. cloacae & 2.903 & 1.699 \\
\hline Mean & & & 1.430 & 1.133 \\
\hline
\end{tabular}

Probiotic consumption also had no influence on the amount of each species or the profile of species identified in individuals. The most frequently isolated species before and after probiotics was E. cloa- 
cae, followed by K. oxytoca. The predominance of these species in the oral cavity has already been related, ${ }^{15}$ and some authors suggest that the fimbria is an important virulence factor, being responsible for bacterial adherence and persistence. ${ }^{16}$

Although many studies have shown that probiotics can improve cellular and humoral immune responses, ${ }^{17,18}$ significant effects of probiotics on the level of secretory antibodies against enterobacteria have not been demonstrated. Previously, only total IgA levels have been shown to be influenced by probiotic consumption. Revolledo et al. ${ }^{17}$ observed an increase in total IgA levels in serum and intestinal fluid of chickens that received probiotic supplements, and Lara-Villoslada et al. ${ }^{18}$ observed an increase in total $\operatorname{Ig} \mathrm{A}$ in feces and saliva of children who used products with Lactobacillus coryniformis CECT5711 and L. gasseri CECT5714.

The presence of antigens in the mucosa induces production of immunoglobulins that interfere with adhesion and facilitate the elimination of pathogens. Thus, immunoglobulin levels increase with antigenic stimulation and decrease after elimination of microorganisms. Although enterobacteria are considered part of the transient microbiota of the

\section{References}

1. Fuller R. Probiotics in man and animals. J Appl Bacteriol. 1989 May;66(5):365-78.

2. Saavedra JM. Clinical applications of probiotic agents. Am J Clin Nutr. 2001 Jun;73(6):1147S-51S.

3. Cross ML. Microbes versus microbes: Imune signals generated by probiotic lactobacilli and their role in protection against microbial pathogens. FEMS Immunol Med Microbiol. 2002 Dec 13;34(4):245-53.

4. Isolauri E, Sütas Y, Kankaanpää P, Arvilommi H, Salminen S. Probiotics: Effects on immunity. Am J Clin Nutr. 2001 Feb;73(2 Suppl):444S-50S.

5. Shteyer E, Wilschanski M. Novel therapeutic modalities in pediatric inflammatory bowel disease. Isr Med Assoc J. 2008 Nov;10(11):816-20.

6. Gupta V, Garg R. Probiotics. Indian J Med Microbiol. 2009 Jul-Sep;27(3):2002-9.

7. Shu Q, Qu F, Gill HS. Probiotic treatment using Bifidobacterium lactis HN019 reduces weanling diarrhoea associated with rotavirus and Escherichia coli in infection in a piglet model. J Pediatr Gastroenterol Nutr. 2001 Aug;33(2):171-7. oral cavity, these microorganisms are persistent in the intestinal mucosa, promoting an uninterrupted stimulus. It was therefore expected that the specific secretory response could not have changed.

In summary, probiotic consumption may be capable of influencing the prevalence of enterobacteria in the oral cavity. It is possible that probiotics have no effect when there is a balance between enterobacteria and the resident microbiota and the host; however, when the balance is disrupted and the enterobacteria become pathogenic, the consumption of probiotics may induce evident beneficial effects, as other works have shown. ${ }^{7,9}$

\section{Conclusion}

Probiotic consumption reduced the prevalence of enterobacteria in the oral cavity, but did not interfere with their amounts or with the specific secretory immune response against them.

\section{Acknowledgements}

We thank Yakult S/A Industria e Comércio (Caçapava, São Paulo, Brazil) for the donation of Yakult LB samples, and Ivan da Silva de Faria and Jane Rose Dionísio Rodrigues for technical assistance.

8. Shu Q, Gill HS. Immune protection mediated by the probiotic Lactobacillus rhammosus HN001 (DR20ã) against Escheichia coli 0157: h7 infection in mice. FEMS Immunol Med Microbiol. 2002 Sep 6;34(1):59-64.

9. Jerpesen L. Occurrence and taxonomic characteristics of strains of Saccharomyces cerevisiae predominant in African indigenous fermented foods and beverages. FEMS Yeast Res. 2003 Apr;3(2):191-200.

10. Buehlmann M, Bruderer T, Frei R, Widmer AF. Effectiveness of a new decolonisation regimen for eradication of extendedspectrum $\beta$-lactamase-producing Enterobacteriaceae. J Hosp Infect. $2011 \mathrm{Feb} ; 77(2): 113-7$.

11. Santos AL, Jorge AOC, Santos SSF, Silva CRG, Leão MVP. Influence of probiotics on Candida presence and $\operatorname{IgA}$ antiCandida in the oral cavity. Braz J Microbiol. 2009 OctDec;40(4):960-4.

12. Collado MC, Grześkowiak $ヒ$, Salminen S. Probiotic strains and their combination inhibit in vitro adhesion of pathogens to pig intestinal mucosa. Curr Microbiol. 2007 Sep;55(3):260-5.

13. Barrantes X, Railey D, Arias ML, Chaves C. [Evaluation of the effect of probiotic cultures added to commercial yogurt over a 
- Influence of consumption of probiotics on presence of enterobacteria in the oral cavity

known population of Listeria monocytogenes and Escherichia coli O157:H7]. Arch Latinoam Nutr. 2004 Sep;54(3):293-7. Spanish.

14. Brown AT, Sims RE, Raybould TP, Lillich TT, Henslee PJ, Ferretti GA. Oral gram-negative bacilli in bone marrow transplant patients given chlorhexidine rinses. J Dent Res. 1989 Jul;68(7):1199-204.

15. Sedgley CM, Samaranayake LP. The oral prevalence of aerobic and facultatively anaerobic gram-negative rods and yeasts in Hong Kong Chinese. Arch Oral Biol. 1994 Jun;39(6):459-66.

16. Livrelli V, De Champs C, Di Martino P, Darfeuille-Michaud A, Forestier C, Joly B. Adhesive properties and antibiotic resistance of Klebsiella, Enterobacter, and Serratia clinical isolates involved in nosocomial infections. J Clin Microbiol. 1996 Aug;34(8):1963-9.

17. Revolledo L, Ferreira CS, Ferreira AJ. Prevention of Salmonella typhimurium colonization and organ invasion by combination treatment in broiler chicks. Poult Sci. 2009 Apr;88(4):734-43.

18. Lara-Villoslada F, Sierra S, Boza J, Xaus J, Olivares M. [Beneficial effects of consumption of a dairy product containing two probiotic strains, Lactobacillus coryniformis CECT5711 and Lactobacillus gasseri CECT5714 in healthy children]. Nutr Hosp. 2007 Jul-Aug;22(4):496-502. Spanish. 